\title{
COMPARING THE COLOR MASKING EFFECT OF ICON AND PROSEAL ON PRIMARY ENAMEL WHITE SPOT LESIONS- A RANDOMIZED CONTROLLED CLINICAL TRIAL
}

\author{
Rana Khaled Abd El-Monem*, Amr Abdelaziz** \\ and Ola Mohamed Abd El-Geleel***
}

\begin{abstract}
Objectives: The objective of the current study is to investigate and compare the color masking of WSLs treated by (ICON) resin infiltrate and fluoride releasing sealant (PROSEAL) using photographic assessment.

Patients and Methods: This study is a randomized controlled trial (RCT) that included a total of 36 children who were recruited from the outpatient clinic of the Pediatric Dentistry and Dental Public Health Department - Faculty of Dentistry Ain-Shams University. Children having white spot lesions were randomly allocated in either the ICON (Group A) or the PROSEAL (Group B). The assigned material was then applied to the lesions and the color change was measured immediately (A1) and on follow-up intervals of 3 (A2) and 6 months (A3), using digital photographic assessment.
\end{abstract}

Results: The color difference $(\Delta \mathrm{E})$ of WSLs in (group A) showed a significant difference between the pretreatment measurement and all the subsequent measurements. However the $\Delta \mathrm{E}$ wasn't significantly different between (A1) and (A 2) or (A3). Conversely, different follow-up intervals in (group B) were found to be significantly different from each other. Color assessment after 6 months showed that (group A) had a higher percentage of completely masked lesions compared to (group B), however the difference between the two groups wasn't statistically significant.

Conclusions: Both ICON and PROSEAL were successful in masking of WSLs in primary teeth. ICON infiltrant, however showed immediate masking effect. On the other hand, PROSEAL displayed slow progressive improvement in the appearance of WSLs, and it achieved a proper masking effect in 6 months..

KEYWORDS: white spot lesions, primary enamel, color masking, ICON, PROSEAL

\footnotetext{
* M.Sc of Pediatric Dentistry Faculty of Dentistry, Ain-Shams University, Cairo, Egypt.

** Professor; Pediatric Dentistry and Dental Public, Health, Faculty of Dentistry Ain Shams University.

*** Lecturer, Pediatric Dentistry and Dental Public, Health Department, Faculty of Dentistry, Ain-Shams University, Cairo, Egypt. Ain-Shams University, Cairo, Egypt. Pediatric Dentistry and Dental Public Health Department, Faculty of Dentistry,British University in Egypt (BUE).
} 


\section{INTRODUCTION}

The earliest stage of dental caries is the "incipient lesion" and it is characterized by both histological and macroscopic changes in enamel due to sub-surface demineralization which can be clinically detected when it progresses to a depth of 300 to $500 \mu \mathrm{m}^{[1]}$.

The sub- surface porous area is called the "body of the lesion", it comprises pores that are filled either with water from the saliva or even filled with air. Due to the difference between the refractive index of hydroxyapatite and water or air, the initial caries lesion appear as a clinically visible "White Spot Lesions" WSLs as the light which shines on the teeth is deflected and scattered ${ }^{[2]}$.

A variety of non-invasive products and regimens have been developed in an attempt to manage these white spot lesions, the most common interventions that have been proposed include Fluoride, Casein Phosphopeptides-Amorphous Calcium Phosphate (CPP-ACP), Bioactive Glass, Xylitol, Nanohydroxyapatite (Nano-HAP) ${ }^{[3,4]}$.

Many noncavitated lesions remain clinically visible after treatment because the minerals from saliva or other remineralizing agents could not occupy the porosities present in the lesion body, as a result esthetics will still be compromised if the carious lesions or other porous enamel defects are present in visible areas ${ }^{[5]}$.

Throughout the wide range of WSLs treatment modalities, resin infiltration is described as a micro-invasive technology in which the enamel lesion is infiltrated with a low-viscosity lightcured resin marketed under the name $\mathrm{ICON}^{\circledR}$ in an attempt to arrest and mask WSLs. The principal of resin infiltration is to perfuse the porous enamel by capillary action. This makes the difference in refractive indices between porosities and sound enamel to be negligible, as a result, lesions lose their whitish opaque color and blend in reasonably with surrounding natural tooth structure ${ }^{[6]}$. Moreover, the lesion progression will supposedly be arrested by occluding the micro porosities that provide diffusion pathways for the acids and dissolved materials ${ }^{[7]}$.

In the same manner, earlier studies ${ }^{[8-11]}$ demonstrated that some adhesive systems could be used successfully to manage WSLs as they retained the ability to penetrate through the subsurface pores of early carious lesions following variable enamel conditioning protocols.

Among the various protective orthodontic sealants, PROSEAL ${ }^{\mathrm{TM}}$ is a filled resin sealant that is fluoride-releasing as it contains $18 \%$ glass ionomer powder which provides for the fluoride-releasing and recharging potential. It was intended to be used in orthodontic patients to seal the etched enamel to prevent WSL development and further lesion progression notwithstanding the patients' lack of compliance with oral hygiene instructions. It was also distinguished for its resistance to abrasion that it was claimed to resist toothbrush abrasion and normal wear for over two years ${ }^{[12-14]}$.

Different modalities for management of WSLs had been extensively investigated on permanent tooth enamel, despite of that, to this date there is still a paucity of data regarding their use on deciduous enamel. Therefore, the objective of the current study is to investigate and compare the color masking of WSLs treated using (ICON) resin infiltrate and fluoride releasing sealant (PROSEAL) using photographic assessment.

\section{PATIENTS AND METHODS}

\section{Study design}

This is a double-blinded controlled clinical trial, with a randomization between groups in a ratio of $1: 1$. The patients in the control group received ICON resin infiltration, while in the test group, the patients received PROSEAL, as treatments for WSLs. 


\section{Ethical considerations}

The study protocol was approved by the ethical committee of faculty of dentistry, Ain-Shams University. Prior to enrolment, all patients were given oral information about the aim and procedures of the study and a written informed consent/ assent was obtained from the guardians and patients respectively.

\section{Sample Size Estimation}

A power analysis was designed to have adequate power to apply a two-sided statistical test of the research hypothesis (null hypothesis) that there is no difference between the efficacy of non-fluoride resin infiltration material and fluoride releasing sealant in treating early enamel lesions in primary teeth. According to the results of Clark ${ }^{[15]}$ Using an alpha $(\alpha)$ level of $0.05(5 \%)$ and a Beta $(\beta)$ level of $0.20(20 \%)$ i.e. power $=80 \%$; the predicted sample size (n) was estimated to a minimum of (28) cases randomly allocated to two test groups i.e. (14) cases per group. To compensate for an almost $25 \%$ possible patients drop-out, the number in each group was increased to (18) patients in each group with a total of (36) patients in the sample.

\section{Patients}

Patients who participated in the study were selected from the Pediatric Dentistry and Dental Public Health Department outpatient clinic at the Faculty of Dentistry- Ain-Shams University. Thirtysix patients (with a total of $n=84$ teeth) displaying WSLs were recruited to the study sample according to the following selection criteria.

\section{Inclusion criteria}

1. Age range $(4-9)$ years.

2. Presence of two or more white spot lesions on the labial surfaces of the upper and/or lower primary anterior teeth.

3. The WSLs classified as codes $1 \& 2$ according to the International Caries Detection and Assessment system "ICDAS II" [16], displayed clinically as chalky white, dull, non-cavitated enamel opacities, were only included.

\section{Exclusion criteria}

1. Vulnerable groups were excluded as subjects with any abnormal oral, mental condition or systemic diseases.

2. Teeth diagnosed with cavitated lesions, hypoplastic defects and/or dental fluorosis.

3. Subjects who received any previous therapy for WSLs ${ }^{[17,18]}$.

The patients were randomly allocated in either of the study groups following 1:1 simple random allocation, with the aid of internet-based program (http://www.random.org/) for the generation of two random sequence sets of numbers from a list of the patients' assigned numbers. To ensure allocation concealment, sequence generation was done by an investigator other than the operator or the clinician who assessed the results.

\section{Blinding}

The participants (children and their parents) were blinded to the type of treatment they were to receive. A blinded operator assessed the WSLs immediately after the intervention and in follow-up visits, who was different from the operator who carried out the clinical procedures. The photographic analysis and interpretation were also done by a blinded specialist to eliminate any possible bias.

\section{Procedures}

Eligible children having white spot lesions were randomly allocated in either Group A (ICON Group) or Group B (PROSEAL Group) to receive different treatments, then the patients were scheduled for follow-up at 3, and 6 months intervals to inspect the WSLs response to the applied intervention. 
Polishing using polishing paste*, brush and rubber cup, was performed to remove any debris and to ensure a clean tooth surface prior to intervention, polishing was also repeated in each subsequent visit during follow up.

ICON® usage involved application of Icon ${ }^{\circledR}$ Etch syringe (15\% Hydrochloric acid) for 2 minutes, followed by rinsing with water for 30 seconds and drying with oil-free and water-free air. The lesion was then desiccated using the Icon ${ }^{\circledR}$-Dry syringe (99\% ethanol) for 30 seconds followed by drying with oil-free and water free air. Icon ${ }^{\circledR}$-Infiltrant syringe was placed on the targeted surface and caries resin-infiltrant was dispensed. After three minutes, excess infiltrant was wiped using a cotton roll and the surface was light-cured ${ }^{* *}$ for 40 seconds. Lastly, the infiltrant was reapplied for one minute and light cured for 40 second. Lastly, the infiltrated surfaces were polished according to manufacturer instructions to remove any surface irregularities ${ }^{[19]}$.

As for PROSEAL ${ }^{\mathrm{TM}}$ application, according to the manufacturer's instruction the whole enamel surface was etched using 37\% phosphoric acid gel (ESPE Scotchbond Phosphoric Etchant Delivery System, 3M Corporation, St. Paul, Minnesota) for 30 seconds, rinsed under running water, and dried with oil- and moisture-free compressed air. A single coat of Pro-Seal was applied to the etched enamel surface, thinned using a gentle stream of compressed air, and light-cured for 20 seconds ${ }^{[20]}$.

\section{Photographic Assessment of white spot lesions}

Anterior teeth were captured from the facial view using professional camera*** with Macro lens ${ }^{* * * * *}$ $100 \mathrm{~mm} / \mathrm{f} 2.8 \mathrm{~L}$ and external Ring flash ${ }^{* * * * *}$ which was held by a Tripod to stabilize its position. Plastic cheek retractors were used and teeth were dried well

\footnotetext{
* Prophy paste, Kent, UK

** Elipar, 3M, USA

*** Canon 700D, Mississauga, Ontario, Canada

***** Canon U.S.A., Inc.

***** Nissin Japan Ltd.
}

with air-water syringe prior to photography. The patient was instructed to stand upright in front of a dark background with Frankfort plane parallel to the floor and the camera lens was centered to the midline of the teeth.

During capturing photos, certain properties in the camera setting were standardized (ISO 100, shutter speed 1/200 of a second, Auto white balance and aperture of F29), the external ring flash with settings (flash power 1/16 with 2/3 EV steps) and the distance between the camera and the background was fixed $(20 \mathrm{~cm})$.

The image quality was set as RAW format. All images were saved as Joint Photographic Experts Group (JPEG) files suitable for manipulation with the image analysis software. Dental photography was done in all sessions (pre operatively, after application immediately, after 3 months and after 6 months follow-up intervals) (Table 1).

TABLE (1): WSLs assessment intervals for ICON \& PROSEAL groups.

\begin{tabular}{ccc}
\hline Timing & $\begin{array}{c}\text { Group A } \\
\text { (ICON) }\end{array}$ & $\begin{array}{c}\text { Group B } \\
\text { (Pro Seal) }\end{array}$ \\
\hline Before application & $\mathrm{A}_{0}$ & $\mathrm{~B}_{0}$ \\
\hline $\begin{array}{c}\text { After application } \\
\text { (immediately) }\end{array}$ & $\mathrm{A}_{1}$ & $\mathrm{~B}_{1}$ \\
\hline 3 months & $\mathrm{A}_{2}$ & $\mathrm{~B}_{2}$ \\
\hline 6 months & $\mathrm{A}_{3}$ & $\mathrm{~B}_{3}$ \\
\hline
\end{tabular}

The JPEG images which were taken pre operatively and in the follow up periods were imported into a software program (Adobe Photoshop CS6) for image analysis to calculate the change in color of WSLs. Optical Results were analyzed for each tooth, performed at the central area of WSL 
and also on healthy tooth structure. the colour of the teeth in the same site was analyzed by transferring the outlined layer of the $A_{0} / B_{0}$ photograph to the $\mathrm{A}_{1} / \mathrm{B}_{1} \mathrm{~A}_{2} / \mathrm{B}_{2}$ and $\mathrm{A}_{3} / \mathrm{B}_{3}$ photographs ${ }^{[21]}$ Using the Color system (CIE-Lab76) ${ }^{[22]}$. The CIE L*a*b System records colorimetric parameters threedimensionally, each image was analyzed separately. The image was opened in the program and by clicking a color picker in Adobe Photoshop ${ }^{\mathrm{TM}}$ the $\mathrm{LAB}$ numerical values were determined for each tooth then the colour changes were defined as:

$$
\Delta \mathrm{E}_{\mathrm{ab}}^{*}=\sqrt{\left(\Delta \mathrm{L}^{*}\right)^{2}+\left(\Delta \mathrm{a}^{*}\right)^{2}+\left(\Delta \mathrm{b}^{*}\right)^{2}}
$$

According to degrees of colour changes evaluated 6 months after treatment, the teeth were divided into the following three types: Type 1: the whitish opaque colours are completely masked (tooth with $\Delta \mathrm{E} \leq 3.7$ units in the area of the white spot versus the area of sound enamel after 6 months); Type 2: whitish opaque colours are partially masked but not completely (tooth with $\Delta \mathrm{E}$ $>3.7$ units in the area of the white spot versus the areas of sound enamel after 6 months, and with $\Delta \mathrm{E}$ $>3.7$ between WSL before treatment and 6 months after treatment); and Type $3:$ the whitish opaque colours show little change (tooth with $\Delta \mathrm{E}>3.7$ units in the area of the white spots versus areas of sound enamel after 6 months, with $\Delta \mathrm{E} \leq 3.7$ between WSL before and 6 months after treatment) ${ }^{[23]}$.

\section{Statistical analysis}

Categorical data were presented as frequencies (n), percentages (\%) and Chi square test was used for statistical analysis followed by pairwise comparisons utilizing z-test with Bonferroni correction when the main test was significant. Quantitative data were explored for normality using Kolmogorov-Smirnov and Shapiro-Wilk tests and was found to follow normal distribution so they were presented as mean and standard deviation (SD). Two-way mixed model intraclass correlation coefficient (ICC) was used to study intra and inter-examiner reliability. Independent t test was used for intergroup comparisons, while One-way ANOVA of repeated measures was used for intragroup comparisons followed by Bonferroni post hoc test when the ANOVA test was significant. The significance level was set at $\mathrm{P} \leq 0.05$ for all tests. Sample size calculation was performed using $\mathrm{G}^{*}$ Power version 3.1.9.2. Statistical analysis was performed with IBM $^{\circledR}$ (IBM Corporation, NY, USA) Statistics Version 25 for Windows.

\section{RESULTS}

Considering the patients drop-out, a total of 30 patients $(n=69$ teeth) were assessed at follow-up intervals, (15 patients in each group). Such that $\mathrm{n}=36$ teeth were in Group A (ICON) and $n=33$ teeth were in Group B (PROSEAL), as shown in the participants' flow diagram (Fig.1).

\section{Comparing the color difference between sound tooth structure and WSL at different measuring intervals:}

Mean, Standard deviation (SD) of the color difference $(\Delta \mathrm{E})$ between the WSL follow up intervals and the sound tooth structure in ICON subjects (group A) and in PROSEAL subjects (group B) were presented in table (2).

a. Intergroup comparison: Shows that before application of ICON and PROSEAL (i.e. at $\left.\mathrm{A}_{0} / \mathrm{B}_{0}\right)$, there was no statistically significant difference $(\mathrm{P}=0.139)$ in $\Delta \mathrm{E}$ values between both groups. Baseline $\Delta \mathrm{E}$ means and standard deviations of groups A \& B were $(10.41 \pm 0.55$ and $10.02 \pm 0.83$ ) respectively.

Whereas, at follow-up intervals, group B had a higher statistically significant $($ mean \pm SD) values than group $\mathrm{A}$. At $\left(\mathrm{A}_{1} / \mathrm{B}_{1}\right) \Delta \mathrm{E}($ mean $\pm \mathrm{SD})$ were $(2.36 \pm 0.20 / 5.43 \pm 0.77)$, after 3 months $\left(\mathrm{A}_{2} / \mathrm{B}_{2}\right)$ $\Delta \mathrm{E}(\mathrm{mean} \pm \mathrm{SD})$ were $(2.26 \pm 0.19 / 4.12 \pm 0.31)$ and finally after 6 months $\left(\mathrm{A}_{3} / \mathrm{B}_{3}\right) \Delta \mathrm{E}($ mean $\pm \mathrm{SD})$ were $(2.23 \pm 0.19 / 3.58 \pm 0.55)$ with $\mathrm{P}$-value $<0.001$ at all the assessment intervals. 


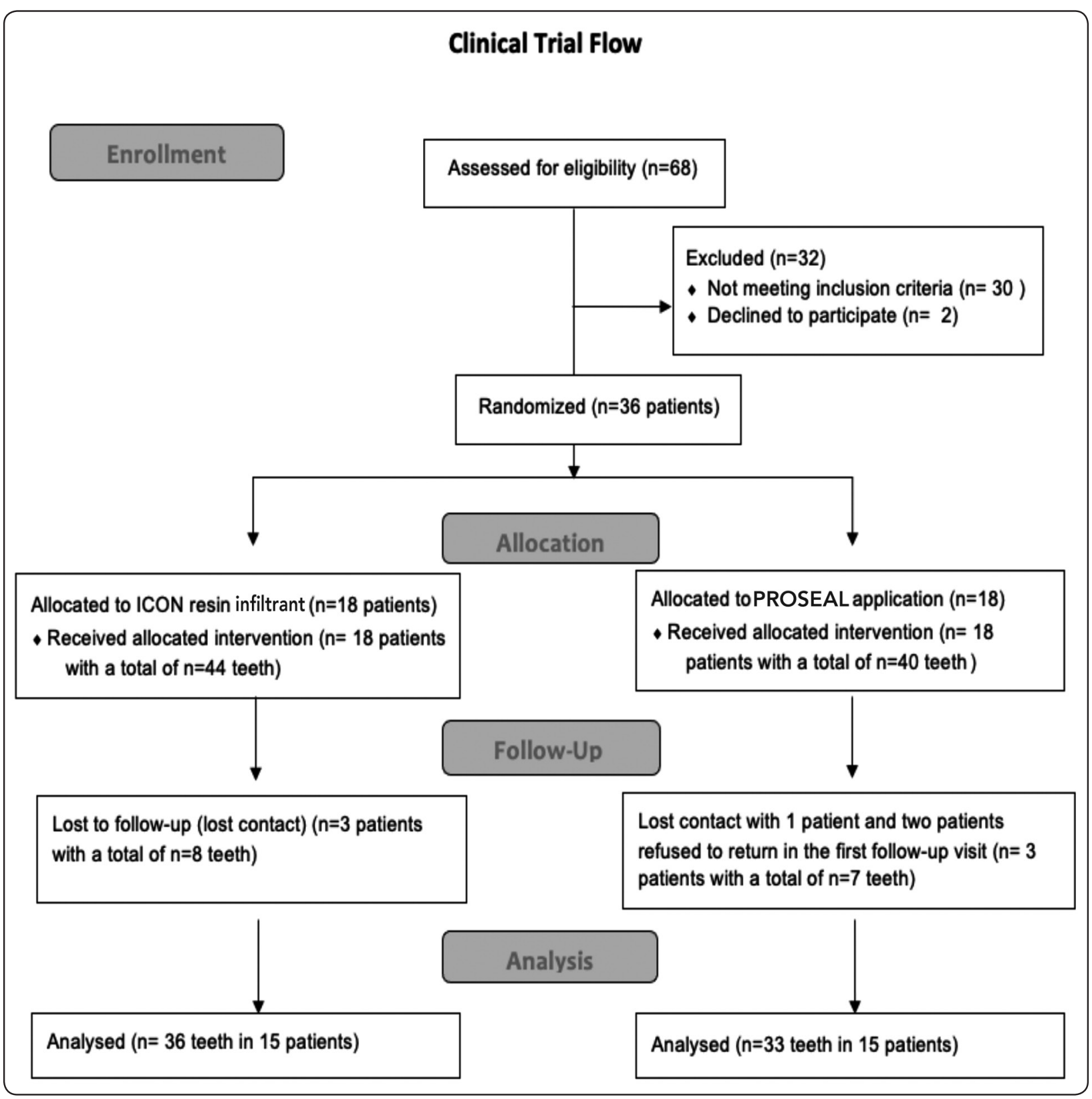

Fig. (1): Participants' flow diagram

b. Intragroup comparison:Within each group, there was a statistically significant difference between different follow-up intervals and there was a continuous decrease of $\Delta \mathrm{E}(\mathrm{mean} \pm \mathrm{SD})$ values starting from $\left(\mathrm{A}_{0} / \mathrm{B}_{0}\right)$ till $\left(\mathrm{A}_{3} / \mathrm{B}_{3}\right)$.

Pairwise comparisons presented in Table (2) show that in group A, the color difference of WSLs at $A_{0}$ were found to be significantly different from subsequent follow-up intervals with. However the $\Delta \mathrm{E}$ wasn't significantly different starting $\left(\mathrm{A}_{1}\right)$ till $\left(\mathrm{A}_{3}\right)$ where $\Delta \mathrm{E}($ mean $\pm \mathrm{SD})$ scored $(2.36 \pm 0.20$, $2.26 \pm 0.19$ and $2.23 \pm 0.19)$ respectively.

Conversely, different follow-up intervals in group B were found to be significantly different from each other with P-value $<0.001$. Where the $\Delta \mathrm{E}(\mathrm{mean} \pm \mathrm{SD})$ scored the lowest at 6 months 
(3.58 \pm 0.55$)$, followed by $\Delta \mathrm{E}($ mean $\pm \mathrm{SD})$ values at 3 months $(4.12 \pm 0.31)$, then immediately after application $(5.43 \pm 0.77)$, while the highest values were obtained at baseline $(10.02 \pm 0.83)$.

TABLE (2): Mean, Standard deviation (SD) for color difference $(\Delta \mathrm{E})$ between WSLs at the follow-up intervals compared to the sound tooth structure in both groups

\begin{tabular}{|c|c|c|c|}
\hline \multirow{2}{*}{$\begin{array}{c}\text { Follow-up } \\
\text { intervals }\end{array}$} & \multicolumn{2}{|c|}{ Group $($ Mean \pm SD) } & \multirow{2}{*}{ P-value } \\
\hline & $\mathbf{A}$ & B & \\
\hline $\begin{array}{c}\Delta E \text { (sound- } \\
\left.\left(\mathbf{A}_{0} / \mathbf{B}_{0}\right)\right)\end{array}$ & $10.41 \pm 0.55^{\mathrm{A}}$ & $10.02 \pm 0.83^{\mathrm{A}}$ & $0.139 n s$ \\
\hline $\begin{array}{c}\Delta \mathrm{E} \text { (sound- } \\
\left.\left(\mathrm{A}_{1} / \mathrm{B}_{1}\right)\right)\end{array}$ & $2.36 \pm 0.20^{\text {B }}$ & $5.43 \pm 0.77^{\mathrm{B}}$ & $<0.001 *$ \\
\hline $\begin{array}{c}\Delta E \text { (sound- } \\
\left.\left(\mathbf{A}_{2} / \mathbf{B}_{2}\right)\right)\end{array}$ & $2.26 \pm 0.19^{\mathrm{B}}$ & $4.12 \pm 0.31^{\mathrm{C}}$ & $<0.001 *$ \\
\hline $\begin{array}{c}\Delta E \text { (sound- } \\
\left.\left(A_{3} / B_{3}\right)\right)\end{array}$ & $2.23 \pm 0.19^{\mathrm{B}}$ & $3.58 \pm 0.55^{\mathrm{D}}$ & $<0.001 *$ \\
\hline P-value & $<0.001 *$ & $<0.001 *$ & \\
\hline
\end{tabular}

Different superscript letter within the same column indicates a statistically significant difference*; significant $(p \leq 0.05)$ ns; non-significant $(p>0.05)$

\section{Comparing color difference of WSL at follow up intervals:}

Mean, Standard deviation (SD) for color difference $(\Delta \mathrm{E})$ of WSL before $\left(\mathrm{A}_{0}, \mathrm{~B}_{0}\right)$ and after application for both groups at different follow-up intervals were presented in table (3). Photographs showing effect of different treatments at different assessment time points are represented in figures (2) and (3).

A- Intergroup comparison: Regarding WSL at $\left(\mathrm{A}_{3}, \mathrm{~B}_{3}\right)$, no statistically significant difference () between ICON (group A) and PROSEAL (group B) was noted where the $\triangle \mathrm{E}($ mean $\pm \mathrm{SD})$ values scored $3.41 \pm 0.37$ and $3.00 \pm 0.24$ respectively.

However, immediately after application at, $\Delta \mathrm{E}$ (mean \pm SD) values were $3.49 \pm 0.20$ and $2.07 \pm 0.77$, and at 3 months follow-up $\left(\mathrm{A}_{2} / \mathrm{B}_{2}\right) \Delta \mathrm{E}($ mean $\pm \mathrm{SD})$ values were $3.48 \pm 0.28$ and $2.22 \pm 0.96$, with $\mathrm{P}$-values of $(0.001$ and 0.005$)$ at $\left(\mathrm{A}_{1} / \mathrm{B}_{1}\right)$ and $\left(\mathrm{A}_{2} / \mathrm{B}_{2}\right)$, reflecting a statistically significant difference between both groups at these time points.

Intragroup comparison: In group A, there was no statistically significant difference $(\mathrm{P}$-value $=0.447)$ between different follow-up intervals however there was a continuous decrease of (mean $\pm \mathrm{SD}) \Delta \mathrm{E}$ values $(3.49 \pm 0.20,3.48 \pm 0.28$ and $3.41 \pm 0.37)$ starting from A1 until A3.

Whereas in group B, there was a statistically significant difference with $(\mathrm{P}$-value $=0.006)$ between different follow-up intervals in which there was a continuous increase of (mean $\pm \mathrm{SD}) \Delta \mathrm{E}$ values $(2.07 \pm 0.77,2.22 \pm 0.96$ and $3.00 \pm 0.24)$ starting from B1 until B3.

TABLE (3): Mean, Standard deviation (SD) for color difference $(\Delta E)$ of WSLs at follow-up intervals compared to baseline status

\begin{tabular}{|c|c|c|c|}
\hline \multirow{2}{*}{$\begin{array}{l}\text { Follow-up } \\
\text { intervals }\end{array}$} & \multicolumn{2}{|c|}{ Groups $($ Mean \pm SD) } & \multirow{2}{*}{ P-value } \\
\hline & $\mathbf{A}$ & B & \\
\hline $\begin{array}{c}\Delta \mathrm{E}\left(\mathrm{A}_{0} / \mathrm{B}_{0}\right. \\
\left.-\mathrm{A}_{1} / \mathrm{B}_{1}\right)\end{array}$ & $3.49 \pm 0.20^{\mathrm{A}}$ & $2.07 \pm 0.77^{\mathrm{A}}$ & $0.001 *$ \\
\hline $\begin{array}{c}\Delta \mathrm{E}\left(\mathrm{A}_{0} / \mathrm{B}_{0}\right. \\
\left.-\mathrm{A}_{2} / \mathrm{B}_{2}\right)\end{array}$ & $3.48 \pm 0.28^{\mathrm{A}}$ & $2.22 \pm 0.96^{\mathrm{A}}$ & $0.005 *$ \\
\hline $\begin{array}{c}\Delta \mathrm{E}\left(\mathrm{A}_{0} / \mathrm{B}_{0}\right. \\
\left.-\mathrm{A}_{3} / \mathrm{B}_{3}\right)\end{array}$ & $3.41 \pm 0.37^{\mathrm{A}}$ & $3.00 \pm 0.24^{\mathrm{B}}$ & $0.409 \mathrm{~ns}$ \\
\hline P-value & $0.447 \mathrm{~ns}$ & $0.006 *$ & \\
\hline
\end{tabular}

Different superscript letter within the same column indicates a statistically significant difference*; significant ( $p \leq 0.05)$ ns; non-significant ( $p>0.05)$ 


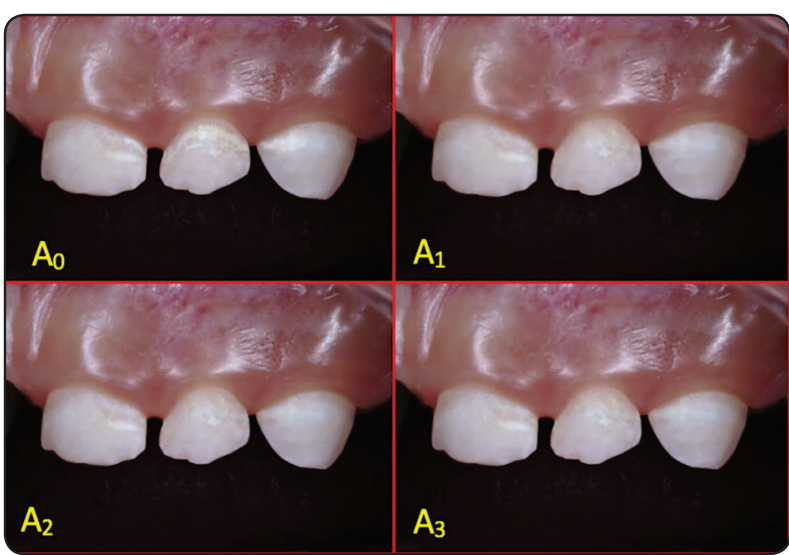

Fig. (2): A0: Upper left primary incisors and canine displaying untreated WSLs

A1: Partially masked and unchanged WSLs immediately after ICON application

A2: Partially masked and unchanged WSLs 3 months after ICON application

A3: Partially masked and unchanged WSLs 6 months after ICON application

\section{Degree of masking of wsl after treatment}

Frequency (n) and percentage (\%) of the degree of masking of WSL after treatment for both groups were presented in table (4).WSLs were classified into completely masked, partially masked and unchanged.

ICON group (group A) had a higher percentage of completely masked lesions (44.4\%), as shown in (figure 4) followed by partially masked and unchanged lesions with equal percentages $(27.78 \%)$ (figure 2).

Likewise, the majority of PROSEAL (group B) had a higher percentage of completely masked lesions (42.42\%) as shown in (figure 5) followed by partially masked $(30.30 \%)$ then unchanged lesions $(27.28 \%)$ as in (figure 3$)$.

ICON (group A) had a higher percentage of

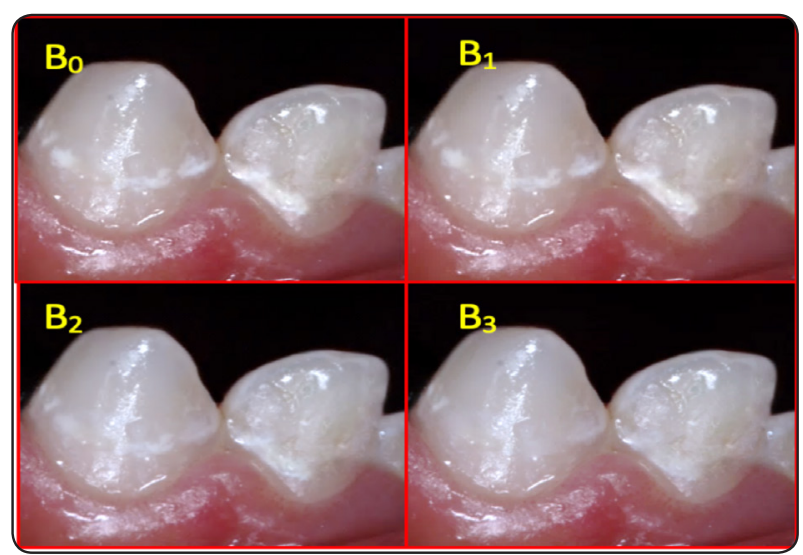

Fig. (3): B0: lower right primary canine and lateral incisor displaying untreated WSLs

B1: WSLs appearance immediately after PROSEAL application B2: WSLs appearance 3 months after PROSEAL application

B3: Partially masked WSLs 6 months after PROSEAL application

completely masked lesions while PROSEAL (group B) had a higher percentage of partially masked lesions, however difference between the two groups was insignificant $(\mathrm{P}$-value $=0.910)$.

TABLE (4): Frequency (n) and percentage (\%) for the degree of masking of WSLs after treatment in both groups.

\begin{tabular}{|c|c|c|c|}
\hline \multirow{2}{*}{ WSL } & \multicolumn{2}{|c|}{ Groups n (\%) } & \multirow{2}{*}{ P-value } \\
\hline & $\mathbf{A}$ & B & \\
\hline $\begin{array}{c}\text { Completely } \\
\text { masked }\end{array}$ & $16(44.44 \%)$ & $14(42.42 \%)$ & $0.910 \mathrm{~ns}$ \\
\hline $\begin{array}{l}\text { Partially } \\
\text { masked }\end{array}$ & $10(27.78 \%)$ & $10(30.30 \%)$ & \\
\hline Unchanged & $10(27.78 \%)$ & $9(27.28 \%)$ & \\
\hline Total & $36(100 \%)$ & $33(100 \%)$ & \\
\hline
\end{tabular}

*; signifiant $(p \leq 0.05) n s ;$ non-signifiant $(p>0.05)$ 


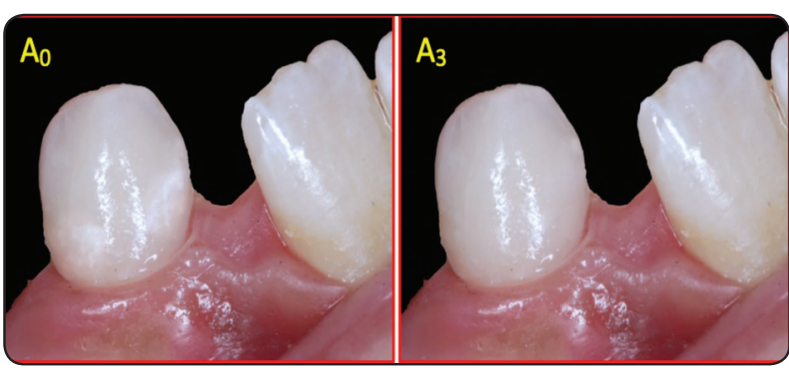

Fig. (4): A0: Lower right primary canine displaying untreated WSL

A1: Completely masked WSL 6months after ICON application

\section{DISCUSSION}

The use of remineralizing agents was advocated as a non-invasive method for arresting active non-cavitated carious lesions and mitigating the aesthetic disturbance that arise as the light traverses the porous affected subsurface enamel that appears more opaque than the normal well-mineralized tooth structure ${ }^{[7,17]}$. However, their slow effect and the need for patient compliance and cooperation, encouraged the introduction of other materials that only require a single application ${ }^{[12,24,25]}$.

The present study evaluated the results from standardized digital photography and image analysing software using the $\Delta \mathrm{E}$ unit, which quantifies the discrepancy between the two colours. In this study, "Digital imaging" has been used as it is an objective, reproducible, and reliable system that is particularly useful in clinical trials as it limits variability and bias seen with more subjective methods as non-digital photography and direct assessment with naked eye ${ }^{[26,27]}$.

The results of the current study showed that on comparing the sound tooth structure to the treated WSL using the CIE Lab equation, a significant decrease of $\triangle E$ mean values was noted in the ICON group and the PROSEAL group immediately after application. As for the ICON group the mean value of the $\Delta \mathrm{E}$ unit was less than 3.7 units which was considered to be a match for a sound tooth structure

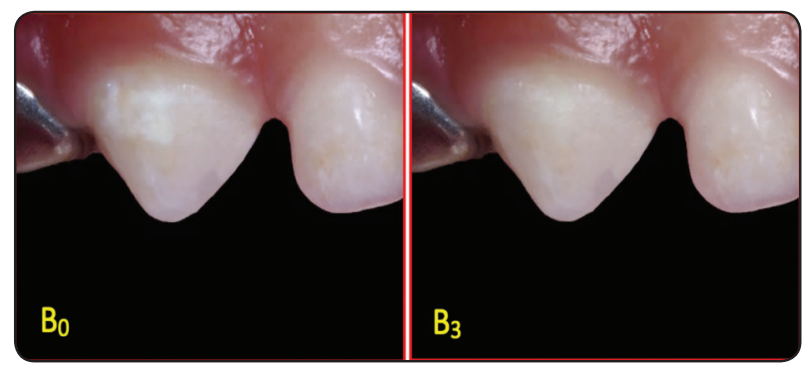

Fig. (5): B0: Upper right primary canine displaying untreated WSL

B3: Completely masked WSL 6 months after PROSEAL application

hence, not clinically distinguishable from sound tooth structure. As for the PROSEAL group, the mean value of the $\Delta \mathrm{E}$ unit was more than 3.7 units which reflects that the WSL is clinically detectable. Since it was reported that the human observers are able to detect colour differences if the $\Delta \mathrm{E}>3.7$ units ${ }^{[28,29]}$.

It could be inferred that ICON infiltrant was more capable to penetrate through enamel substrate that was preconditioned with a strong acid $(15 \%$ hydrochloric acid $\mathrm{HCl}$ ) followed by ethanol to expel moisture in the subsurface porosities. Enamel substrate however in the latter group was pretreated only with a weaker acid (37\% phosphoric acid $\mathrm{H}_{3} \mathrm{PO}_{4}$ ) which could explain the better penetrability of ICON compared to PROSEAL.

This extrapolation is supported by the results obtained earlier by Paris et al. ${ }^{[30]}$, who compared the etching effect of the hydrochloric acid and phosphoric acid on enamel of primary teeth by confocal microscopy, and they stated that a higher erosion was achieved when primary enamel with initial caries was preconditioned by $\mathrm{HCl}$ acid for 90-120 minutes which in turn allowed the resin infiltrant to penetrate twice as deep into the enamel compared to phosphoric acid etching.

ICON group in the current study displayed no significant difference in the initially obtained masking effect compared to results obtained in 
different follow-up intervals which reflects the stability of the initially obtained masking effect up to six months. This result goes in agreement with that obtained by Senestraro et al. ${ }^{[18]}$ who conducted a randomized clinical trial involving patients with post orthodontic WSLs. The researchers reported a significant improvement in the clinical appearance of WSLs treated with ICON resin infiltrant compared to the non-treated control teeth. They further added that the improvement in appearance was stable up to eight weeks following the intervention. Other randomized clinical trials and non-randomized studies also reported stability in the masking effect of the resin infiltrant that was traced to the end of their timeframes that varied from few months up to one year ${ }^{[31-33]}$.

On the other hand, the PROSEAL group in this research showed an increasing improvement in the color of the WSLs at follow-up intervals, although this improvement was not pronounced immediately after application, yet it continued to improve increasingly at the follow-up intervals. This could be explained by the notion that this resin is capable of fluoride release owing to the incorporated glass ionomer particles, which could have a remarkable effect on the demineralization/remineralization process. Fluoride release from PROSEAL was even traced to a period of 17 weeks or more as reported by Soliman et al. ${ }^{[34]}$ which could, over time, enhance remineralization especially in an acidic medium and hence improve esthetics.

Conversely it was disputed that its fluoride release is low (less than 1ppm) which could justify the need for frequent reapplication ${ }^{[14]}$. Similarly, Premaraj et al. ${ }^{[35]}$, conceded that the duration of release may not be of use unless recharged, despite of that, Leizer et al. ${ }^{[14]}$, still affirmed that PROSEAL is capable of preventing biofilm formation through interfering with Strept. Mutans adhesion, in addition to having sufficient wear resistance and resistance to acid penetration.
The present study also showed that there was no statistically significant difference between the ICON group and the PROSEAL group in the degree of masking of WSLs 6 months following application. This goes in agreement with the results of de Lacerda et al. ${ }^{[10]}$ as they tested the color masking ability of ICON infiltration in addition to other different adhesive systems for the treatment of artificial white spot lesions using color difference $(\Delta \mathrm{E})$ obtained by spectrophotometer. The previously mentioned researchers came to the conclusion that all agents applied were significantly effective in color masking of artificial white spot lesions as the refractive indices of the adhesives used were very similar to the ICON according to their justification.

A recent study, conducted by Hagag, et al. in $2020^{[36]}$, also reported that both ICON and a nonfilled adhesive, were capable of adequate color masking of WSLs, and the mean $\triangle \mathrm{E}$ between sound enamel and the treated lesions were 1.3 and 2.3 for ICON and the unfilled resin groups respectively, and these color differences were still not detectable clinically as color change is considered clinically visible when $\Delta \mathrm{E}$ is higher than 3.7 units according to Johnston and $\mathrm{Kao}^{[28]}$.

On the contrary, ICON resin infiltrant was reported with more superior color improvement compared to an unfilled adhesive resin in an invitro study by Abdellatif and El-Sebaai ${ }^{[37]}$. The authors further explained their results by supposing that the physical proprieties of the infiltrant as its viscosity and surface tension could have affected its penetration and thus its clinical outcome.

The discrepancy between the previous study results and the current research could be attributed to the variations in the selected materials and the enamel substrate. In this study a fluoride releasing adhesive resin was compared to ICON, so the comparison group has the privilege of fluoride release initially and throughout the study as it recharges its fluoride depot from the ambient environment, and 
this could have improved its results due to boosting remineralization, moreover, the primary enamel in this study might have acted as a better substrate to resin penetration owing to its increased porosity compared to permanent enamel which have been tested in the above-mentioned study.

It is worth also mentioning that, both groups in this research demonstrated complete masking of the enamel lesions in more than $(40 \%)$ of the cases, Kim et al. ${ }^{[23]}$ however, reported a greater proportion of $(61 \%)$ from the total of the treated decalcified lesions. The same authors supposed that the degree of masking could be dependent on the lesion depth and activity. The masking effect could be deficient in deeper lesions that surpass the range for resin penetration. In addition in the inactive old lesions with rather thicker surface layers that require more than a single erosive round to effectively remove the hardened and thick surface layer to achieve better penetration, which was not adopted in this study. Furthermore, a single application of the ICON etch was done as recommended by the manufacturer for application. This however could be considered for future research as we can test doubling the erosive rounds in an attempt to achieve better resin penetration.

Despite the strengths of this study, as it compares the masking effect of PROSEAL to ICON resin infiltrant on WSLs in primary teeth which has not been investigated earlier, to the best of our knowledge, whether in in-vitro or in-vivo studies. Moreover, being an in-vivo study, the obtained results could clearly represent what is expected in real clinical situations as opposed to in-vitro studies.

However, that are certain shortcomings that can not be overlooked, including but not limited to the small sample size, relatively short-term follow-up to assess the color stability and also the assessment was only limited to the color changes not taking in account other changes in the enamel lesions in response to different treatments as the lesion size or mineral content.

\section{CONCLUSIONS}

Based on the results of this study it can be concluded that:

- Both ICON and PROSEAL were successful in masking of WSL in primary teeth.

- ICON infiltrant showed immediate masking effect of WSL and colour stability throughout the 6 months.

- Fluoride releasing resin sealant (PROSEAL), did not show immediate masking effect, yet, slow progressive improvement took place, where it yielded proper masking effect after 6 months.

\section{RECOMMENDATIONS}

- Increasing the follow-up periods in order to test the color stability of both materials over a longer period of time.

- Testing the effect of etching enamel with ICON etch for more than a single application on the final masking ability and color stability. Same for increasing the etching time with phosphoric acid prior to PROSEAL application.

\section{REFERENCES}

1. Roopa KB, Pathak S, Poornima P, \& Neena IE. White spot lesions: a literature review. J Pediatr Dent. 2015;3(1):1-7.

2. Cury JA, Tenuta LM. Enamel remineralization: controlling the caries disease or treating early caries lesions? Braz Oral Res. 2009;23(suppl 1):23-30.

3. Yengopal V, Harneker SY, Patel N, Siegfried N. Dental fillings for the treatment of caries in the primary dentition. Cochrane Database Syst Rev. 2009 Apr 15;(2):CD004483. doi: 10.1002/14651858.CD004483.pub2. Update in: Cochrane Database Syst Rev. 2016 Oct 17;10 :CD004483. PMID: 19370602.

4. Frencken JE, Peters MC, Manton DJ, Leal SC, Gordan VV, Eden E. Minimal intervention dentistry for managing dental caries - a review: report of a FDI task group. Int Dent J. 2012 Oct;62(5):223-43. doi: 10.1111/idj.12007. PMID: 23106836; PMCID: PMC3490231. 
5. Zantner C, Martus P, Kielbassa AM. Clinical monitoring of the effect of fluorides on long-existing white spot lesions. Acta Odontol Scand. 2006 Apr;64(2):115-22. doi: 10.1080/00016350500443297. PMID: 16546854.

6. Torres CR, Rosa PC, Ferreira NS, Borges AB. Effect of caries infiltration technique and fluoride therapy on microhardness of enamel carious lesions. Oper Dent. 2012;37(4):363-369. doi:10.2341/11-070-L

7. Knösel M, Vogel R, Sandoval P. Infiltration of WhiteSpot-Lesions and developmental enamel defects. Revista Clínica de Periodoncia, Implantología y Rehabilitación Oral. 2017;10: 101-106.

8. Gray GB, Shellis P. Infiltration of resin into white spot caries-like lesions of enamel: an in vitro study. Eur J Prosthodon Restor Dent 2002;10:27-32.

9. Paris S, Meyer-Lueckel H, Kielbassa AM. Resin infiltration of natural caries lesions. J Dent Res 2007;86:662-666.

10. de Lacerda AJ, Avila DM, Borges AB, Pucci CR, Rocha Gomes Torres C. Adhesive systems as an alternative material for color masking of white spot lesions: Do They Work? J Adhes Dent. 2016;18:43-50.

11. Zamorano X, Valenzuela V, Daniela A, Ituraun A. SEM comparison of penetration in artificial white spot lesion between an infiltrant resin and two adhesive systems. Open J. of Stomatology. 2017; 7: 147-157.

12. Korbmacher-Steiner HM, Schilling AF, Huck LG, Kahl-Nieke B, Amling M. Laboratory evaluation of toothbrush/toothpaste abrasion resistance after smooth enamel surface sealing. Clin Oral Investig. 2013 Apr;17(3):765-74. doi: 10.1007/s00784012-0771-8. Epub 2012 Jul 1. PMID: 22752334.

13. Behnan SM, Arruda AO, González-Cabezas C, Sohn W, Peters MC. In-vitro evaluation of various treatments to prevent demineralization next to orthodontic brackets. Am J Orthod Dentofacial Orthop. 2010 Dec;138(6):712. e1-7; discussion 712-3. doi: 10.1016/j.ajodo.2010.05.014. PMID: 21130326.

14. Leizer C, Weinstein M, Borislow A, \& Braitman L. Efficacy of a filled-resin sealant in preventing decalcification during orthodontic treatment. Am J Orthod Dentofacial Orthop , 2010;137(6): 796-800,.

15. Clark TJ. The efficacy of ProSeal ${ }^{\mathrm{TM}}$, SeLECT Defense ${ }^{\mathrm{TM}}$, OrthoCoat ${ }^{\mathrm{TM}}$, and Biscover $\mathrm{LV}^{\mathrm{TM}}$ resin sealants on the prevention of enamel demineralization and white spot lesion formation: University of Iowa; 2010.
16. KM Shiva Kumar, Sumanth Prasad, GN Chandu: International caries detection and assessment system: A new paradigm in detection of dental caries. Conserv Dent 2009; 12(1).

17. Salar DV, García-Godoy F, Flaitz CM, Hicks MJ. Potential inhibition of demineralization in vitro by fluoride-releasing sealants. J Am Dent Assoc. 2007;138(4):502-506. doi:10.14219/jada.archive.2007.0203.

18. Senestraro SV, Crowe JJ, Wang M, Vo A, Huang G, Ferracane J, Covell DA Jr. Minimally invasive resin infiltration of arrested white-spot lesions: a randomized clinical trial. J Am Dent Assoc. 2013 Sep;144(9):997-1005. doi: 10.14219/jada.archive.2013.0225. PMID: 23989837.

19. Swamy DF, Barretto ES, Mallikarjun SB, Dessai SSR. In vitro Evaluation of Resin Infiltrant Penetration into White Spot LesionsofDeciduous Molars. JClinDiagnRes.2017;11(9):ZC71ZC74. doi:10.7860/JCDR/2017/28146.10599

20. Abdel-haffiez SH, Zaher A, \& Elharouny NM. Effects of a filled fluoride-releasing enamel sealant versus fluoride varnish onthe prevention of enamel demineralization under simulated oral conditions.J. World Fed. Orthod.2013,2, e133-e136.

21. Heravi F, Ahrari F, Tanbakuchi B. Effectiveness of MI Paste Plus and Remin Pro on remineralization and color improvement of postorthodontic white spot lesions. Dent Res J (Isfahan). 2018;15(2):95-103.

22. Johnston WM. Color measurement in dentistry. J Dent. 2009;37 Suppl 1:e2-e6. doi:10.1016/j.jdent.2009.03.011

23. Kim S, Kim EY, Jeong TS, Kim JW. The evaluation of resin infiltration for masking labial enamel white spot lesions. Int J Paediatr Dent. 2011 Jul; 21(4):241-8. doi: 10.1111/j.1365-263X.2011.01126.x. Epub 2011 Mar 14. PMID: 21401750.

24. Mann N, Gupta P, \& Makkar S. Resin Infiltration Technique: The Minimal Invasive Approach to Treat White Spot Lesions. TMU J. Dent. 2015;2(2): 71-74.

25. Coordes SL, Jost-Brinkmann PG, Präger TM, et al. A comparison of different sealants preventing demineralization around brackets. Ein Vergleich unterschiedlicher Versiegler zur Prävention von Demineralisierung im Bracketumfeld. J Orofac Orthop. 2018; 79(1):49-56. doi:10.1007/s00056-017-0116-y

26. Sitthisettapong T, Phantumvanit P, Huebner C, Derouen T. Effect of CPP-ACP paste on dental caries in primary teeth: a randomized trial. J Dent Res. 2012;91(9):847-852. doi:10.1177/0022034512454296 
27. Plonka KA, Pukallus ML, Holcombe TF, Barnett AG, Walsh LJ, Seow WK. Randomized controlled trial: a randomized controlled clinical trial comparing a remineralizing paste with an antibacterial gel to prevent early childhood caries. Pediatr Dent. 2013;35(1):8-12.

28. Johnston WM, Kao EC. Assessment of appearance match by visual observation and clinical colorimetry. J Dent Res 1989; 68: 819-822.

29. Paul S,PeterA,PietrobonN,HämmerleCH.Visual and spectrophotometric shade analysis of human teeth. J Dent Res. 2002;81(8):578-582. doi:10.1177/154405910208100815

30. Paris S, Dörfer CE, Meyer-Lueckel H. Surface conditioning of natural enamel caries lesions in deciduous teeth in preparation for resin infiltration. J Dent. 2010;38(1):65-71. doi:10.1016/j.jdent.2009.09.001

31. Knösel M, Eckstein A, \& Helms H. Durability of esthetic improvement following Icon resin infiltration of multibracket-induced white spot lesions compared with no therapy over 6 months: A single-center, split-mouth, randomized clinical trial. American Journal Of Orthodontics And Dentofacial Orthopedics. 2013; 144(1): 86-96.

32. Wang L, Jian J, \& Hui-fang L. Efficiency of resin infiltration versus fluride varnish for treatment of post-orthodon- tic white spot lesions. Chinese Journal of Tissue Engineering Research. 2013;17(29): 5303-5308.

33. Eckstein A, Helms HJ, Knösel M. Camouflage effects following resin infiltration of postorthodontic white-spot lesions in vivo: One-year follow-up. Angle Orthod. 2015; 85(3):374-380. doi:10.2319/050914-334.1

34. Soliman MM, Bishara SE, Wefel J, Heilman J, Warren JJ. Fluoride release rate from an orthodontic sealant and its clinical implications. Angle Orthod. 2006;76(2):282-288. doi:10.1043/0003-3219(2006)076[0282:FRRFAO]2.0.CO;2

35. Premaraj TS, Rohani N, Covey D, Premaraj S. In vitro evaluation of surface properties of Pro Seal ${ }^{\circledR}$ and Opal® SealTM in preventing white spot lesions. Orthod Craniofac Res. 2017;20 Suppl 1:134-138. doi:10.1111/ ocr.12181

36. Hagag N, Fahmy O, Abo Alazm E. Effect of Two Resin Infiltration on Color Masking of Artificial Enamel White Spot Lesion Using Different Pretreatment Methods. (An in Vitro Study). Dental Science Updates, 2020; 1(1): 31-38. doi: $10.21608 /$ dsu.2020.14906.1006

37. Abdellatif AB, El-Sebaai HS. Effects of resin application on white spot lesions (laboratory study). J Clin. Pediatr. Dent 2016; 46: 120-126. 